\title{
A Cross-Sectional Study on Oyo State Health Care Worker's Knowledge, Attitude and Practice regarding Corona Virus Disease 2019 (COVID-19)
}

\author{
Olubunmi O. Ayinde, Aishat B. Usman²,3, Aduroja Posi' ${ }^{4}$, Abass Gbolahan ${ }^{5}$ \\ ${ }^{1}$ Department of Public Health, Oyo State Ministry of Health, Ibadan, Nigeria \\ ${ }^{2}$ Nigeria Field Epidemiology and Laboratory Training Program, Abuja, Nigeria \\ ${ }^{3}$ African Field Epidemiology Network, Abuja, Nigeria \\ ${ }^{4}$ Department of Health Promotion and Education, University of Ibadan, Ibadan, Nigeria \\ ${ }^{5}$ Department of Planning Research and Statistics, Oyo State Ministry of Health, Ibadan, Nigeria \\ Email: jummsyp@yahoo.com
}

How to cite this paper: Ayinde, O.O., Usman, A.B., Posi, A. and Gbolahan, A. (2020) A Cross-Sectional Study on Oyo State Health Care Worker's Knowledge, Attitude and Practice regarding Corona Virus Disease 2019 (COVID-19). Advances in Infectious Diseases, 10, 6-15.

https://doi.org/10.4236/aid.2020.103002

Received: April 24, 2020

Accepted: May 23, 2020

Published: May 26, 2020

Copyright $(02020$ by author(s) and Scientific Research Publishing Inc. This work is licensed under the Creative Commons Attribution International License (CC BY 4.0).

http://creativecommons.org/licenses/by/4.0/

\section{(c) (i) Open Access}

\begin{abstract}
Background: Health workers are at the front line of the COVID-19 outbreak response and as such are exposed to hazards that put them at risk of infection. Poor knowledge among HCWs and inadequate infection control practices may lead to the increased risk of COVID-19 nosocomial transmission. This study assessed the knowledge, attitude and practice of Oyo state health care workers on COVID-19 as part of emergency preparedness. Methods: A hospital based cross-sectional survey was conducted in selected health facilities in Oyo State, Nigeria. A total of 350 HCWs were assessed for the knowledge, attitudes and practices on COVID-19 using a semi-structured questionnaire. Multivariate analysis was conducted to identify predictors of good knowledge at 95\% confidence interval with Epi-info software. Results: The level of good knowledge on COVID-19 was $78.6 \%$ and positive attitude was $64 \%$ among the respondents. Majority of respondents practice safe measures in the prevention of COVID-19 including washing of hands (95.3\%), routine cleaning (82.7\%) and high-level disinfection (83.9\%). However, use of personal protective equipment (PPE) was low (56.8\%). Predictors of good knowledge on COVID-19 were being a female HCW [Adjusted Odd's Ratio (AOR) = $6.595 \%$ CI $1.0-17.2$ ], $\geq 10$ years length in service [AOR $=5.295 \%$ CI 2.7 18.9] and being a secondary or tertiary facility [AOR $=3.695 \% \mathrm{CI} 1.7$ 32.2]. Conclusions: Overall knowledge and attitude were satisfactory however the practices of HCWs on the use of personal protective equipment were
\end{abstract}


not satisfactory. Effective infection control measures including regular skillbased training and/or orientation for all categories of HCWs can improve infection control practices in health facilities.

\section{Keywords}

Health Care Workers, Knowledge, Attitudes and Practices, COVID-19, Oyo State

\section{Introduction}

Coronaviruses $(\mathrm{CoV})$ are a large family of viruses that cause illness ranging from the common cold to more severe diseases such as Middle East Respiratory Syndrome (MERS-CoV) and Severe Acute Respiratory Syndrome (SARS-CoV). A novel coronavirus $(\mathrm{nCoV})$ is a new strain that has not been previously identified in humans.

Coronaviruses are zoonotic, meaning they are transmitted between animals and people. Detailed investigations found that SARS-CoV was transmitted from civet cats to humans and MERS-CoV from dromedary camels to humans. Several known coronaviruses are circulating in animals that have not yet infected humans.

Person-to-person spread of COVID-19 appears to occur mainly by respiratory transmission. How easily the virus is transmitted between persons is currently unclear. Signs and symptoms of COVID-19 include fever, cough, and shortness of breath [1]. Based on the incubation period of illness for Middle East respiratory syndrome (MERS) and severe acute respiratory syndrome (SARS) coronaviruses, as well as observational data from reports of travel-related COVID-19, CDC estimates that symptoms of COVID-19 occur within 2 - 14 days after exposure. Preliminary data suggest that older adults and persons with underlying health conditions or compromised immune systems might be at greater risk for severe illness from this virus [2]. Common signs of infection include respiratory symptoms, fever, cough, shortness of breath and breathing difficulties. In more severe cases, infection can cause pneumonia, severe acute respiratory syndrome, kidney failure and even death.

The WHO declared the outbreak to be a Public Health Emergency of International Concern on 30 January, 2020 and presently the virus has spread across all the continents except Artatica. Standard recommendations to prevent infection spread include regular hand washing, covering mouth and nose when coughing and sneezing, thoroughly cooking meat and eggs. Avoid close contact with anyone showing symptoms of respiratory illness such as coughing and sneezing [3].

The nature of health care workers job puts them at an increased risk of catching any communicable disease, including COVID-19. During the SARS outbreak in 2002, one-fifth of all cases were in health care workers. If they start to get sick 
in high numbers during a disease outbreak, it amplifies the already high levels of strain on the health care system. That's why it's so important that they have good knowledge on how to identify patients, isolate and use protective equipment correctly. Personal protective equipment (PPE), like masks, gloves, and gowns, help keep nurses and doctors safe when they're treating patients with infectious diseases like COVID-19. To protect against the new virus, the Centers for Disease Control and Prevention (CDC) recommends that health care workers wear N95 masks, which filter out airborne particles and tiny droplets that may have been coughed up by patients. Those masks only protect health care workers if they're used properly, though. They must be fitted, worn, and removed in a specific way [4]. We conducted this study to assess knowledge, attitude and practice of health care workers on COVID-19 in selected health facilities in Oyo State, South West, Nigeria.

\section{Methods}

\subsection{Study Area and Design}

This study formed part of the emergency preparedness for COVID-19 before the confirmation of cases in Oyo State. This was a cross-sectional study conducted between February and March 2020 at eight randomly selected secondary and primary health care facilities in Oyo State. There are 1560 health facilities distributed across different levels in Oyo State: Federal-2, State-4, Local-667 and registered private/mission-887.

\subsection{Sample Size Determination and Sampling}

To determine the sample size for this study, the following parameters was used; prevalence of $0.5 \%$ since there is no previous study on COVID-19, power of $80 \%, 95 \%$ confidence interval and precision of $5 \%$ to arrive at a minimum sample size of 350 .

A two-stage sampling technique was used. Eight health facilities were randomly selected from Government owned facilities. Staff records in each of the hospital was obtained as sampling frame. Proportional allocation of questionnaire was done based on the number of staff in each health facility. For each facility, respondents were selected systematically using appropriate sampling interval until the desired sample size was achieved.

\subsection{Data Collection}

Data was collected using a semi-structured questionnaire that comprised of four sections: 1) socio-demographic characteristics; 2) knowledge about the Corona Virus Disease-19; 3) attitudes towards the Corona Virus Disease-19 control 4) practice of infection prevention control against COVID-19. Questionnaire content was pretested among $20 \mathrm{HCWs}$ in a health facility different from the selected ones for this study and appropriate adjustment was made as necessary. Three research assistants were trained on the final questionnaire and mobilised 
for the data collection. They were regularly monitored and supervised during the data collection process.

\subsection{Data Management}

All completed questionnaires were cross-checked and edited on the same day and before data entry to ensure data consistency and completeness. All recorded data were coded and entered in Epi Data. Analyses were performed using EpiInfo software version 7. Descriptive statistics was conducted to generate frequencies, proportions and means to summarize the socio-demographic characteristics of the health care workers and bivariate analyses were used to measure the association between HCW's Knowledge and socio-demographic variables at 95\% confidence interval using crude odd's ratio. To identify predictors of good knowledge multivariate analysis was conducted at $\mathrm{p}<0.05$. HCWs' knowledge variables were scored and respondents answering $\geq 70 \%$ of the knowledge questions correctly were considered as having good level of knowledge and others were considered to have poor knowledge. The attitude variables comprised of 10 statements with response categories "Strongly Agree", "Agree", "Neither Agree nor Disagree", "Disagree" or "Strongly Disagree". These were recoded as:

1) Strongly agree and agree $=$ Agree.

2) Neither agree nor disagree $=$ Uncertain.

3) Strongly disagree and Disagree $=$ Disagree.

Composite scores were calculated and those scoring $\geq 70 \%$ were considered as having positive attitudes towards COVID-19 control. The cut-off points for knowledge and attitude levels were set as informed by similar studies [5] [6].

\subsection{Ethical Considerations}

Ethical approval (AD13/479/1769B) was obtained from Ethical Review and Research ethics Committee of Oyo State Ministry of Health. Informed consent was obtained, and confidentiality of the information provided was maintained.

\section{Results}

\subsection{Socio-Demographic Characteristics of the Health Care Workers}

Table 1 shows the socio-demographic characteristics of the health care workers. The mean age was $48.5 \pm 7.0$ and $52.6 \%$ were female. The average length of year in service was $13 \pm 6$ and $40.9 \%$ were Nurses. Christianity accounted for the most practiced religion (72\%) among respondents and $86.0 \%$ were married.

\subsection{Knowledge}

Table 2 shows the respondents level of knowledge on COVID-19 disease. Majority of the health care workers knew the cause of COVID-19 (90\%), its spread (99\%), sign and symptoms (95\%) however, with respect to prevention only half of the respondents (54.7\%) see staying at home as a containment measure at re- 
ducing spread of the disease and $27 \%$ believed that face mask can prevent someone from contracting COVID-19. More than two-third (78.6\%) of the health care workers in Oyo State had good knowledge on COVID-19.

\subsection{Attitude}

Table 3 shows the attitude of HCWs towards COVID-19 prevention. Overall, 64.9\% had positive attitude towards COVID-19. The bivariate analysis showed significant relationship between respondents' good knowledge of COVID-19 and their positive attitudinal disposition $(\mathrm{COR}=2.195 \% \mathrm{CI}(1.3-18.4)$ at $\mathrm{p}$-value less than 0.05 .

Table 1. Socio-demographic characteristics of health care workers in Oyo State 2020.

\begin{tabular}{|c|c|c|}
\hline Variable & Frequency $(n=350)$ & Percentage \\
\hline \multicolumn{3}{|l|}{ Age(years) } \\
\hline $20-29$ & 5 & 1.5 \\
\hline $30-39$ & 40 & 11.4 \\
\hline $40-49$ & 122 & 34.8 \\
\hline$\geq 50$ & 183 & 52.3 \\
\hline \multicolumn{3}{|l|}{ Mean age $48.5 \pm 7.0$} \\
\hline \multicolumn{3}{|l|}{ Sex } \\
\hline Male & 166 & 47.4 \\
\hline Female & 184 & 52.6 \\
\hline \multicolumn{3}{|l|}{ Designation } \\
\hline Nurses & 143 & 40.9 \\
\hline CHO\&CHEWs & 93 & 26.5 \\
\hline Doctors & 83 & 23.7 \\
\hline Others(health attendant/ward maid) & 31 & 8.8 \\
\hline \multicolumn{3}{|l|}{ Length of year in service } \\
\hline$>10$ years & 182 & 53.7 \\
\hline 5 - 10 years & 121 & 34.6 \\
\hline$<5$ years & 41 & 11.7 \\
\hline \multicolumn{3}{|l|}{ Type of facility } \\
\hline Primary & 222 & 63.4 \\
\hline Secondary & 94 & 26.9 \\
\hline Tertiary & 33 & 9.4 \\
\hline \multicolumn{3}{|l|}{ Marital Status } \\
\hline Single & 33 & 9.4 \\
\hline Married & 301 & 86.0 \\
\hline Divorced/Widow(er) & 16 & 4.6 \\
\hline \multicolumn{3}{|l|}{ Religion } \\
\hline Islam & 98 & 28.0 \\
\hline Christianity & 252 & 72.0 \\
\hline
\end{tabular}

Others are ward maid, record attendant and pharmacist. 
Table 2. Knowledge of health care workers on COVID-19 $(n=350)$.

\begin{tabular}{lc}
\hline Knowledge Questions & $\begin{array}{c}\text { Correct } \\
\text { Responses (\%) }\end{array}$ \\
\hline SARs COV-2 is the virus and the disease are COVID-19 & $310(88.6)$ \\
COVID-19 is spread from person to person & $340(97.1)$ \\
Gloves cannot provide complete protection against transmission of COVID-19 & $290(82.9)$ \\
Washing hands with soap or use of an alcohol-based antiseptic decreases the risk & $327(93.4)$ \\
of transmission of COVID-19 & $222(63.4)$ \\
Someone who has been released from COVID-19 quarantine is not considered a \\
risk for spreading the virus to others \\
$\begin{array}{l}\text { Some of the symptoms of COVID-19 are fever, cough, and difficulty breathing, } \\
\text { myalgia, fatigue, nausea, and diarrhea }\end{array}$ & $326(93.1)$ \\
$\begin{array}{l}\text { You should maintain 1 - 1.5 meters distance between you and anyone that is } \\
\text { coughing and sneezing }\end{array}$ & $326(93.1)$ \\
If you feel unwell with symptoms such as fever, cough and difficulty in breathing \\
you should stay indoors
\end{tabular}

Table 3. Attitude of HCWs towards COVID-19 prevention.

\begin{tabular}{|c|c|c|c|}
\hline Statement & Agree (\%) & Uncertain (\%) & Disagrees (\%) \\
\hline $\begin{array}{l}\text { I think Nigerian government will contain COVID-19 } \\
\text { outbreak }\end{array}$ & $167(47.7)$ & $81(23.1)$ & $102(29.1)$ \\
\hline $\begin{array}{l}\text { Government should ban all flights coming from all } \\
\text { countries with confirmed cases of COVID-19 }\end{array}$ & $148(42.3)$ & $153(43.7)$ & $49(14.0)$ \\
\hline $\begin{array}{l}\text { I think schools should be shut down to prevent spread } \\
\text { of COVID-19 }\end{array}$ & $225(64.3)$ & $18(5.1)$ & $107(30.6)$ \\
\hline If I see anyone from China, I should run away & $220(62.9)$ & $57(16.3)$ & $72(20.6)$ \\
\hline $\begin{array}{l}\text { I think Government should ban public gathering in } \\
\text { Nigeria for now to prevent spread of COVID } 19\end{array}$ & $250(71.5)$ & $10(2.9)$ & $90(25.7)$ \\
\hline I think COVID-19 is a form of biological war fare & $194(55.4)$ & $61(17.4)$ & $95(27.1)$ \\
\hline $\begin{array}{l}\text { I think bathing with onion water can prevent me from } \\
\text { having COVID-19 }\end{array}$ & $149(42.6)$ & $170(48.6)$ & $31(8.9)$ \\
\hline I think people are anxious about COVID-19 outbreak & $196(56.0)$ & $116(33.1)$ & $38(10.9)$ \\
\hline $\begin{array}{l}\text { I feel outbreak of COVID-19 can to lead to } \\
\text { breakdown of essential services in the hospital }\end{array}$ & $227(64.9)$ & $19(5.4)$ & $104(29.7)$ \\
\hline $\begin{array}{l}\text { I feel health care workers in Nigeria are not capable of } \\
\text { managing COVID-19 cases }\end{array}$ & $195(55.7)$ & $113(32.3)$ & $42(12.0)$ \\
\hline
\end{tabular}

\subsection{Practice}

As shown in Figure 1, Majority of respondents practice safe measures in the prevention of COVID-19 including washing of hands (95.3\%), routine cleaning $(82.7 \%)$ and high-level disinfection (83.9\%). However, use of personal protective equipment (PPE) was low (56.8\%). 


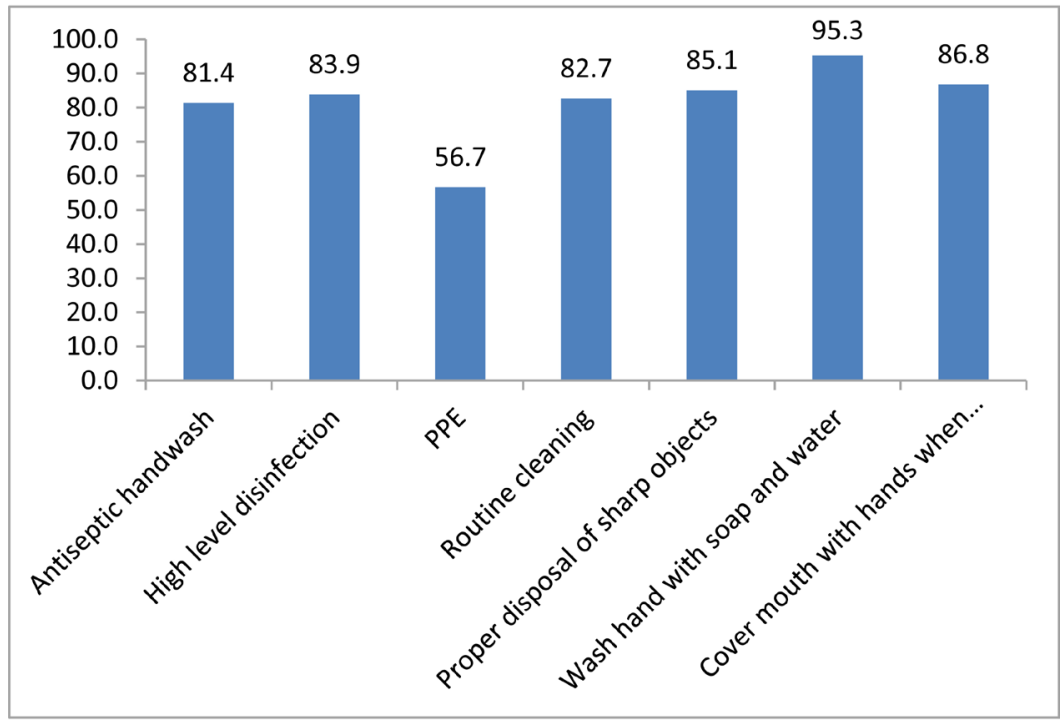

Figure 1. Practice of HCWs on COVID-19 prevention.

Table 4. Predictors of HCWs Good Knowledge on COVID-19.

\begin{tabular}{ccccc}
\hline Variables & Good Knowledge & Poor Knowledge & OR & AOR \\
\hline Age (years) & & & & \\
$<40$ & $40(14.5)$ & $5(6.8)$ & 1 & 1 \\
$\geq 40$ & $236(85.5)$ & $69(93.2)$ & $1.8(0.56-3.19)$ & $1.4(0.75-3.36)$ \\
Sex & & & & \\
Male & $126(45.8)$ & $40(53.3)$ & 1 & 1 \\
Female & $149(54.2)$ & $35(46.7)$ & $3.5(1.9-31.1)^{*}$ & $6.5(1.0-17.2)^{*}$ \\
Designation & & & & \\
CHEW \& Others & $87(31.6)$ & $37(49.3)$ & & 1 \\
Doctor \& Nurse & $188(68.4)$ & $38(50.7)$ & $1.3(0.4-5.0)$ & $0.1(0.1-1.9)$ \\
Length of years in service & & & & 1 \\
$<10$ years & $126(45.8)$ & $41(54.7)$ & & 1 \\
$\geq 10$ years & $149(54.2)$ & $34(45.3)$ & $3.7(2.5-10.1)$ & $5.2(2.7-18.9)$ \\
Marital Status & & & & 1 \\
Single \& Divorced & $39(14.2)$ & $10(13.3)$ & & 1 \\
Married & $236(85.8)$ & $65(86.7)$ & $1.1(0.3-4.20)$ & $2.0(0.5-8.9)$ \\
Type of facility & & & & 1 \\
Primary & $143(52.0)$ & $33(44.0)$ & & 1 \\
Secondary\& Tertiary & $132(48.0)$ & $42(56.0)$ & $1.4(0.9-10.2)$ & $3.6(1.7-32.2)^{*}$ \\
Religion & & & & $0.3(0.1-1.1)$ \\
Christianity & $71(25.8)$ & $48(64.0)$ & & $1.20(0.1-4.2)$ \\
Islam & $204(74.2)$ & $27(36.0)$ & &
\end{tabular}

${ }^{\star}$ means significant at $\mathrm{p}$-value $<0.05$.

\subsection{Predictors of HCWs Good Knowledge on COVID-19}

The identified predictors of Good knowledge on COVID-19 were being a female $\mathrm{AOR}=6.5(1.0-17.2)$, length of years in service $\geq 10$ years $\mathrm{AOR}=5.2(2.7$ $18.9)$ and working in a secondary or tertiary institutions AOR $=3.6(1.7-32.2)$ as shown in Table 4. 


\section{Discussion}

Knowledge is a prerequisite for establishing prevention beliefs, forming positive attitudes, and promoting positive behaviours. Individuals' cognition and attitudes towards disease affect the effectiveness of their coping strategies and behaviours to a certain extent [7]. This study similarly found that knowledge directly affected attitudes.

The COVID-19 outbreak is considered an emergency and healthcare workers are seen to have an increased risk of infection while there is limited investigation of the knowledge, attitude and practice of healthcare workers towards the COVID-19. Several thousand health-care workers have been affected already worldwide. Therefore, it is important to avoid hospital spread of the disease [8].

The findings in our study showed that HCWs had a high level of knowledge and a positive attitude towards the COVID-19 outbreak as also observed in a study in China [9]. We found that most of the respondents know that COVID19 is a global issue but were not too keen on the ban of public gathering and shutting down of schools as a preventive measure. This shows that the HCWs need to be educated further on mode of spread and prevention of the disease. These findings further suggested that education for HCW on the mode of transmission and prevention is very important.

The study further highlighted the fact that majority of HCWs know and practice safe measures in the prevention of COVID-19 but use of personal protective equipment (PPE) was low (56.8\%). This was because they were not available at the different facilities. Other studies showed that an important reason for early infection among general ward medical staff was that patients were admitted to the ward without protective measures in place. In contrast, infection rates in the more well-protected ICU and emergency departments were lower in cases with no early warning of the disease [10].

We also analysed the characteristics of KAP towards COVID-19 and identified some demographic factors associated with KAP; these finds observed that occupation was significantly associated with knowledge. Doctors and nurses showed relatively more knowledge. Additionally, good knowledge has a higher probability of positive attitudes, this result has not previously been described [11]. The goals of the upcoming educational program should focus on the HCWs with insufficient knowledge and this should improve the rate of positive attitudes of HCWs. Also, provision of PPE and training on it use for all HCW will further prevent the spread of COVID-19 among HCW.

This study had some limitations in interpreting the results because COVID-19 is a novel coronavirus and limited research has been studied to compare. Future studies could estimate the knowledge and attitude of HCWs on a larger scale to be able to design appropriate interventions at the national level.

\section{Conclusion}

The findings showed the majority of HCWs had good knowledge and positive 
attitude toward COVID19, but there are some lower knowledge and negative attitudes than expected. Additional education intervention and campaigns are required for HCWs to avail them with the knowledge of the mode of transmission, the isolation period and treatment strategies, as well as the risk of personal and family infection with COVID-19.

\section{Acknowledgements}

We would like to acknowledge Oyo State Epidemiologist, and head of hospitals in the selected health facilities and all the health care workers for their cooperation and participation in the study.

\section{Conflicts of Interest}

The authors declare no conflicts of interest regarding the publication of this paper.

\section{References}

[1] Chen, N., Zhou, M., Dong, X., et al. (2020) Epidemiological and Clinical Characteristics of 99 Cases of 2019 Novel Coronavirus Pneumonia in Wuhan, China: A Descriptive Study. Lancet, 395, 507-513. https://doi.org/10.1016/S0140-6736(20)30211-7

[2] The Novel Coronavirus Pneumonia Emergency Response Epidemiology Team (2020) The Epidemiological Characteristics of an Outbreak of 2019 Novel Coronavirus Diseases (COVID-19)—China, 2020. China CDC Weekly.

[3] Centers for Disease Control and Prevention (2020) Health Care Workers Are at High Risk of Catching COVID-19.

https://www.theverge.com/2020/3/5/21166088/coronavirus-covid-19-protection-do ctors-nurses-health-workers-risk

[4] World Health Organization. https://www.who.int/health-topics/coronavirus

[5] Shrestha, A., Bhattarai, D., Thapa, B., Basel, P. and Rajendra, R.W. (2017) Health Care Workers' Knowledge, Attitudes and Practices on Tuberculosis Infection Control. Nepal. BMC Infectious Diseases, 17, 724.

https://doi.org/10.1186/s12879-017-2828-4

[6] Bhebhe, L.T., Van Rooyen, C. and Steinberg, W.J. (2014) Attitudes, Knowledge and Practices of Healthcare Workers regarding Occupational Exposure of Pulmonary Tuberculosis. African Journal of Primary Health Care \& Family Medicine, 6, E1-E6. https://doi.org/10.4102/phcfm.v6i1.597

[7] McEachan, R., Taylor, N., Harrison, R., Lawton, R., Gardner, P. and Conner, M. (2016) Meta-Analysis of the Reasoned Action Approach (RAA) to Understanding Health Behaviors. Annals of Behavioral Medicine, 50, 592-612. https://doi.org/10.1007/s12160-016-9798-4

[8] Hoe Gan, W., Wah Lim, J. and Koh, D. (2020) Preventing Intra-Hospital Infection and Transmission of COVID-19 in Healthcare Workers. Safety and Health at Work.

[9] Giao, H., Han, N.T.N., Van Khanh, T., Ngan, V.K., Van Tam, V. and Le An, P. (2020) Knowledge and Attitude toward COVID-19 among Healthcare Workers at District 2 Hospital, Ho Chi Minh City. Asian Pacific Journal of Tropical Medicine.

[10] Zhou, M., Tang, F., Wang, Y., Nie, H., Zhang, L., You, G. and Zhang, M. (2020) 
Knowledge, Attitude and Practice regarding COVID-19 among Health Care Workers in Henan, China. Journal of Hospital Infection.

[11] Khan, M.U., Shah, S., Ahmad, A. and Fatokun, O. (2014) Knowledge and Attitude of Healthcare Workers about Middle East Respiratory Syndrome in Multispecialty Hospitals of Qassim, Saudi Arabia. BMC Public Health, 14, 1281.

https://doi.org/10.1186/1471-2458-14-1281 